\title{
The Ties That Bind: Measuring the Strength of Consumers' Emotional Attachments to Brands
}

\author{
Matthew Thomson \\ Queen's School of Business, Queen's University \\ Deborah J. MacInnis and C. Whan Park \\ Marshall School of Business, University of Southern California.
}

\begin{abstract}
Extant research suggests that consumers can become emotionally attached to consumption objects, including brands. However, a scale to measure the strength of consumers' emotional attachments to brands has yet to be devised. We develop such a scale in Studies 1 and 2. Study 3 validates the scale's internal consistency and dimensional structure. Study 4 examines its convergent validity with respect to four behavioral indicators of attachments. Study 5 demonstrates discriminant validity, showing that the scale is differentiated from measures of satisfaction, involvement, and brand attitudes. That study also examines the scale's predictive validity, showing that it is positively associated with indicators of both commitment and investment. The limitations of the scale and the boundary conditions of its applicability are also discussed.
\end{abstract}

Although consumers interact with thousands of products and brands in their lives, they develop an intense emotional attachment (EA) to only a small subset of these objects (e.g., Schouten \& McAlexander, 1995). The possibility that consumers can develop strong emotional attachments to brands is interesting as attachment theory in psychology (Bowlby, 1979) suggests that the degree of emotional attachment to an object predicts the nature of an individual's interaction with the object. For example, individuals who are strongly attached to a person are more likely to be committed to, invest in, and make sacrifices for that person (Bowlby, 1980; Hazan \& Shaver, 1994). Analogously, consumers' emotional attachments to a brand might predict their commitment to the brand (e.g., brand loyalty) and their willingness to make financial sacrifices in order to obtain it (e.g., to pay a price premium). Unfortunately, no empirically tested measure of consumers' emotional attachment to brands is available. Consequently, it has been difficult for both researchers and practitioners to appraise the strength of the relationship between consumers and brands.

In this article, we (a) develop a psychometrically reliable measure of the strength of consumers' emotional attachments to brands and (b) demonstrate its validity (discriminant, con-

Requests for reprints should be sent to Matthew Thomson, Queen's School of Business, 143 Union Street, Goodes Hall, Kingston, Ontario, Canada, K7L 3N6. E-mail: mthomson@business.queensu.ca vergent, and predictive). Following procedures recommended by Churchill (1979a, 1979b), we specify the domain of a construct that reflects consumers' EA to brands. Items in the domain are reduced to a parsimonious set based on results from two measure-development studies. Three subsequent studies are designed to assess the reliability and validity of this scale. Study 3 validates the internal consistency and structure of the EA scale using a new sample of respondents. Study 4 assesses its convergent validity, appraising the extent to which it maps onto four attachment behaviors identified in the psychology literature. Study 5 assesses the scale's discriminant validity, assessing the extent to which it is differentiated from potentially related constructs commonly studied in the marketing discipline (e.g., attitude favorability, satisfaction, and involvement). Study 5 also investigates the scale's predictive validity, examining the extent to which it predicts outcomes purported to emerge from strong emotional attachments such as commitment (brand loyalty) and investment (willingness to pay a price premium).

\section{THEORETICAL BACKGROUND}

\section{What Is an Attachment?}

The pioneering work on attachment was conducted by Bowlby $(1979,1980)$ in the realm of parent-infant relationships. According to Bowlby, an attachment is an emo- 
tion-laden target-specific bond between a person and a specific object. Attachments vary in strength, and stronger attachments are associated with stronger feelings of connection, affection, love, and passion (cf. Aron \& Westbay, 1996; Bowlby, 1979; Brennan, Clark, \& Shaver, 1998; Collins \& Read, 1990, 1994; Feeney \& Noller, 1996; Fehr \& Russell, 1991; Sternberg, 1987). The desire to make strong emotional attachments to particular others serves a basic human need (Ainsworth, Blehar, Waters, \& Wall, 1978; Bowlby, 1980), beginning from a child's attachment to his or her mother (Bowlby, 1979, 1980) and continuing through the adult stage with romantic relationships (Hazan \& Shaver, 1994), kinships, and friendships (Trinke \& Bartholomew, 1997; Weiss, 1988).

Various behaviors reveal the existence of strong attachments (Bowlby, 1980; Hazan \& Zeifman, 1999). The stronger one's attachment to an object, the more likely one is to maintain proximity to the object. When people experience stress in the external environment, they often seek physical or psychological protection from the attachment object. Moreover, when individuals experience real or threatened separation from the attachment object, distress can result.

The intensity of an attachment has typically been inferred from the aforementioned attachment behaviors, particularly in the context of mother-child relationships. The use of these observational indicators is understandable as infants and small children are unable to articulate attachment-related feelings. Unfortunately, these indicators are often imperfect. Hazan and Zeifman (1999), for example, noted that "proximity maintenance and separation distress, as well as safe-haven and secure-base behaviors are the data from which the existence and regulatory role of the attachment behavioral system are inferred" (p. 351). In studying adults and their attachments to brands, it should be possible to measure directly the intensity of the emotional attachment itself.

\section{The Relevance of Attachment Construct to Consumer Behavior}

People can form emotional attachments to a variety of objects, including pets (Hirschman, 1994; Sable, 1995), places (Rubinstein \& Parmelee, 1992), and celebrities (Adams-Price \& Greene, 1990; Alperstein, 1991). Similarly, research in marketing (Belk, 1988; Kamptner, 1991; R. E. Kleine, Kleine, \& Kernan, 1993; S. S. Kleine, Kleine, \& Kernan, 1989; Mehta \& Belk, 1991) suggests that consumers can develop attachments to gifts (Mick \& DeMoss, 1990), collectibles (Slater, 2000), places of residence (Hill \& Stamey, 1990), brands (Schouten \& McAlexander, 1995), or other types of special or favorite objects (Ball \& Tasaki, 1992; Kleine, Kleine, \& Allen, 1995; Price, Arnould, \& Curasi, 2000; Richins, 1994a, 1994b; Wallendorf \& Arnould, 1988). The notion that such attachments reflect an emotional bond is also suggested by research in consumer behavior (e.g., Shimp \& Madden, 1988). For example, Slater (2000) documented that a variety of emotions (e.g., love, warm feelings) characterize collectors' emotional attachments to Coke and Hallmark. Related work on consumption objects suggests that emotions like love (cf. S. S. Kleine, Kleine, \& Allen, 1995; Richins, 1994a, 1994b; Schultz, Kleine, \& Kernan, 1989) characterize consumers' feelings toward special consumption objects.

Individuals' emotional attachments to a person predict their commitment to the relationship with this person (Drigotas \& Rusbult, 1992; Rusbult, 1983). Commitment is defined as the degree to which an individual views the relationship from a long-term perspective and has a willingness to stay with the relationship even when things are difficult (van Lange, Rusbult, Drigotas, \& Arriaga, 1997). A number of researchers view commitment as a measure of marketing effectiveness (Dwyer, Schurr, \& Oh, 1987; Moorman, Desphande, \& Zaltman, 1993; Morgan \& Hunt, 1994). In a marketing context, a relevant indicator of commitment is the extent to which the individual remains loyal to the brand (Garbarino \& Johnson, 1999). Given the previous, one might propose that a valid measure of emotional attachment should predict consumers' commitment to a brand, such as their loyalty to that brand.

Finally, the strength of emotional attachment to an object may be associated with investment in the object, that is, the willingness to forego immediate self-interest to promote a relationship (van Lange et al., 1997). To this extent, a valid measure of emotional attachment should predict consumers' investment in a brand, such as their willingness to pay a price premium to obtain it.

\section{Differences Between Emotional Attachment and Other Marketing Constructs}

Emotional attachment should be distinguished from other constructs with which it might be correlated, such as brand attitude favorability, satisfaction, and involvement.

Brand attitudes. Consumers who are emotionally attached to a brand are also likely to have a favorable attitude toward it. However, although favorable brand attitudes are often reflected in strong attachments, the constructs differ in several critical ways. First, strong attachments develop over time and are often based on interactions between an individual and an attachment object (Baldwin, Keelan, Fehr, Enns, \& Koh-Rangarajoo, 1996). These interactions encourage the development of meaning and invoke strong emotions in reference to the attachment object. Attitudes reflect one's evaluative reactions to an object and these reactions can develop without any direct contact with it. Thus, a consumer might have a positive attitude toward an object without ever having had any experience with it at all.

Second, consumers can have favorable attitudes toward any number of consumption objects and toward objects that have little centrality or importance to their lives. The objects 
to which consumers are emotionally attached, however, are few in number and are generally regarded as profound and significant (cf. Ball \& Tasaki, 1992; Richins, 1994a).

Third, strong attachments are attended by a rich set of schemas and affectively laden memories that link the object to the self (Holmes, 2000; Mikulincer, Hirschberger, Nachmias, \& Gillath, 2001). In contrast, favorable attitudes do not necessarily link the object to the self and the self-concept.

Fourth, individuals who are strongly emotionally attached to an object also display specific behaviors such as proximity maintenance and separation distress (cf. Bowlby, 1979). These behavioral manifestations are not characteristic of favorable attitudes, the impact of which is highly situation- and context-dependent (Sheppard, Hartwick, \& Warshaw, 1988).

Finally, individuals who are strongly attached to a person or object are generally committed to preserving their relationship with it (cf. Johnson \& Rusbult, 1989; Miller, 1997). This is not necessarily characteristic of favorable attitudes. For example, it would be unusual for a consumer with only a favorable attitude toward a brand to stay committed to it (e.g., brand loyalty) or pay more for it (e.g., price premium) if a more attractive alternative were introduced. In a similar vein, a strong emotional attachment is characterized by a perception that the object is irreplaceable. In contrast, a consumer with a positive attitude toward an object may be willing to replace it with another object that has equally desirable features.

Satisfaction. An individual who is emotionally attached to a brand is likely to be satisfied with it. This satisfaction might provide a basis for emotional attachment. Nevertheless, satisfaction and attachment are not synonymous. Although two consumers are equally satisfied with a brand's performance, they may vary greatly in the extent to which they are emotionally attached to it. Satisfaction does not imply behavioral manifestations such as proximity maintenance and separation distress. Moreover, although satisfaction can occur immediately following consumption, emotional attachments tend to develop over time with multiple interactions. Finally, satisfaction is an evaluative judgment and hence different from the emotionally laden attachment construct (cf. Mano \& Oliver, 1993).

Involvement. Emotional attachment can also be conceptually distinguished from involvement. Involvement is a state of mental readiness that typically influences the allocation of cognitive resources to a consumption object, decision, or action (Park \& Mittal, 1985). Emotional attachment goes beyond mental readiness and resource allocation as it is often beyond one's volitional control. Further, emotional attachments to brands are clearly relevant to the realm of emotions, whereas the concept of involvement arguably taps the realm of cognition.
The previous discussion leads to the idea that a valid scale of consumers' emotional attachments to brands should be correlated with measures of attitude favorability, satisfaction, and involvement as it subsumes these constructs. Nevertheless, attachment is conceptually distinct from these constructs and hence should be empirically distinct from them as well.

\section{Summary}

In this article, we advance a reliable and valid scale that reflects consumers' emotional attachments to brands. We first describe the construction of the scale on the basis of emotion terms that reflect the strength of consumers' attachments to a brand. Second, we demonstrate its convergent validity, showing that it maps onto measures of proximity maintenance, security seeking, experiencing separation distress, and finding a safe haven in the object under conditions of distress (Bowlby, 1980; Hazan \& Zeifman, 1999; see Study 4 later). Third, we demonstrate discriminant validity, showing that the measure is empirically distinct from measures of brand attitude favorability, satisfaction, and involvement. Finally, we provide evidence of predictive validity, showing that the scale predicts outcomes such as commitment to (loyalty toward) the brand and willingness to invest in it (to pay a premium price for it).

\section{STUDY 1}

To develop a parsimonious yet representative scale of the strength of consumers' emotional attachments to brands, we followed procedures for scale development advocated by Churchill (1979a, 1979b). Our first goal was to identify a set of items designed to tap the construct of emotional attachment.

To attain this objective, we asked 68 students to identify a brand to which they were strongly emotionally attached. Participants then completed a survey composed of 39 adjectives that were potentially relevant, based on the literature on both person attachments (e.g., Ball \& Tasaki, 1992; Bowlby, 1979; Brennan et al., 1998, Collins \& Read, 1990, 1994; Feeney \& Noller, 1996; Hazan \& Shaver, 1994; Hazan \& Zeifman, 1994; Schultz et al., 1989), object attachments (e.g., S. S. Kleine, Kleine, \& Allen, 1995; Richins, 1994a, 1994b) and love (e.g., Aron \& Westbay, 1996; Aron, Aron, \& Allen, 1998; Fehr \& Russell, 1991; Hazan \& Shaver, 1987, 1994; Hendrick \& Hendrick, 1989; Shaver, Schwartz, Kirson, \& O’Connor, 1987; Sternberg, 1986, 1987).

Respondents used a 7-point rating scale, ranging from 1 (not at all) to 7 (very well), to describe "the extent to which the following words describe your typical feelings toward the brand." Respondents received one of three versions of the survey, each of which presented the items in a different order. Additionally, respondents were asked to list any other emo- 
tions characterizing their attachments not included in the original list. A total of 10 additional items were named, bringing the list to 49 items.

To reduce the pool, items with mean ratings of less than 4.0 along the 7-point Likert scale were eliminated along with words that respondents free-listed that were synonymous with those on the original list. We also deleted items that two independent judges, blind to the objectives of the research, rated as nonemotional (e.g., "living up to your word"). As a result, we retained 35 items.

\section{STUDY 2}

To reduce further the items identified in Study 1, we asked 120 students to think about a brand to which they were strongly emotionally attached and then to indicate which of the items identified in the first study described their feelings about it along a scale ranging from 1 (describes poorly) to 7 (describes very well). Based on these ratings, we rejected items that had both mean ratings below the scale midpoint and limited variance $(S D s<1.5)$. Further, we eliminated items that over $10 \%$ of participants did not rate under the assumption that the items were confusing or poorly understood.

The remaining items were subjected to a set of exploratory factor analyses using an oblique rotation. Based on our sample size, any factor loading greater than 0.5 was assumed to have practical significance (Hair, 1995). The final set of items reflected a three-factor solution (eigenvalues $>1$ ) and contained 10 items (see Table 1). The first factor, labeled Affection, included the items affectionate, loved, friendly, and peaceful. Items in this factor reflect the warm-feelings a consumer has toward a brand. A second factor, labeled Passion included the items passionate, delighted, and captivated. This factor reflects intense and aroused positive feelings toward a brand. A third factor labeled Connection included the items

TABLE 1

Study 2: Emotional Attachment Dimensions Revealed by Exploratory Factor Analysis

\begin{tabular}{lccc}
\hline & \multicolumn{3}{c}{ Factor } \\
\cline { 2 - 4 } Emotion Item & Affection & Passion & Connection \\
\hline Affectionate & $\mathbf{0 . 8 0}$ & 0.00 & 0.27 \\
Friendly & $\mathbf{0 . 7 8}$ & 0.17 & 0.27 \\
Loved & $\mathbf{0 . 7 6}$ & 0.18 & 0.11 \\
Peaceful & $\mathbf{0 . 7 6}$ & 0.30 & 0.23 \\
Passionate & 0.05 & $\mathbf{0 . 8 0}$ & 0.01 \\
Delighted & 0.26 & $\mathbf{0 . 7 3}$ & 0.04 \\
Captivated & 0.34 & $\mathbf{0 . 6 8}$ & 0.42 \\
Connected & 0.40 & -0.07 & $\mathbf{0 . 8 5}$ \\
Bonded & 0.07 & 0.42 & $\mathbf{0 . 7 8}$ \\
Attached & 0.25 & -0.10 & $\mathbf{0 . 7 3}$ \\
\hline
\end{tabular}

Note. Factor analysis uses an oblique rotation. Bold values indicate the factor on which each item predominantly loads. connected, bonded, and attached. These three items describe a consumer's feelings of being joined with the brand. The correlations between dimensions were all positive and significant (Affection-Connection, $r=0.48$; Affection-Passion, $r$ $=0.24$; Passion-Connection, $r=0.24$ ). The correlations among dimensions increased somewhat in subsequent studies, probably due to the later studies' larger sample sizes and more focused instructions to respondents. The alpha reliability coefficient score for the global EA scale, obtained by averaging scores on Affection, Passion, and Connection, was adequate $(\alpha=0.77)$ and within Nunnally's (1978) guidelines for scale development.

Although we had not anticipated that the scale would exhibit a three dimensional factor structure, the results suggest the possibility that the items represent three first-order factors that are all linked to a higher second-order factor Emotional Attachment. We explore this notion next in Study 3.

\section{STUDY 3}

\section{Objectives and Method}

Study 3 was designed to confirm the stability of the EA scale using a different sample of respondents and to assess the relation among the three factors as first order factor underlying the emotional attachment construct.

Sixty-five undergraduate and graduate students were asked to think about a brand to which they had "some degree of emotional attachment" and to complete the 10-item EA scale with this brand in mind. Scores on the EA items varied from a low of 1 to a high of 7 , with item means ranging from 4.00 (loved) to 5.10 (delighted) and standard deviations ranging from 1.54 (bonded) to 1.74 (passionate). Cronbach's alpha reliability coefficient for the EA scale was 0.88 .

\section{Results}

To assess the relation of the scale items to the emotional attachment construct, we used structural equation modeling and conducted a set of confirmatory factor analyses corresponding to the three models shown in Figure 1.

Model 1 assumes that all 10 items load directly onto a single latent EA construct. Model 2 assumes three equally weighted first-order latent factors, labeled Affection, Passion, and Connection, reflecting a single second-order factor (EA) with no correlations permitted among the first-order latent factors. (This is analogous to a varimax rotation in an exploratory factor analysis.) Model 3 is similar to Model 2 except that the first-order factors are modeled as correlated (somewhat comparable to conducting an oblique rotation). The purpose of this model is to test the notion that the three dimensions can be conceptualized as interrelated first order factors loading onto a global EA latent construct. 
All three models show that each path is positive and significant, suggesting that each indicator contributes to the EA construct directly (Model 1) or to the first-order factors (Affection, Passion, Connection), which are themselves significantly tied to EA (Models 2 and 3). The fit statistics of each model were subsequently examined to assess which model best fits the data. In general, a CMIN/DF (minimum discrepancy divided by the degrees of freedom) statistic of less than 5 is considered adequate, with lower values being superior. For NFI, RFI and CFI statistics, higher values are superior, with the generally acceptable cutoff point being 0.90 for each. According to these criteria, any of the three models is acceptable, because each possesses CMIN/DF statistics below 5 and NFI (normed fit index), RFI (relative fit index), and CFI (comparative fit index) statistics above 0.90. However the chi-square statistics that explicitly compare models suggest that Model $3\left(\chi^{2}=66.7\right)$ is significantly better than both Models $1\left(\chi^{2}=156.3\right)$ and $2\left(\chi^{2}=102.8, p\right.$ s $\left.<0.01\right)$. Model 3 holds that Affection, Passion, and Connection are three nonorthogonal first-order factors that correspond with a higher order EA construct. The similar factor structure found in both Studies 2 and 3 suggests a stable underlying structure to the EA scale.

\section{STUDY 4}

Study 4 was designed to assess the convergent validity of the EA scale. As noted previously, emotional attachments are theoretically associated with specific behaviors (Bowlby, 1980; Hazan \& Zeifman, 1999). Specifically, the strength of an attachment is revealed by the degree of proximity maintenance to the attachment object. Proximity confers security and facilitates successful functioning in the environment. Environmental stress triggers a search for the attachment object as a safe haven from and protector against stress. Finally, behaviors reflective of psychological distress are observed if real or threatened separation from the attachment object occurs. Generally, the intensity of an attachment can be inferred from the levels of these four attachment behaviors. If the EA measure adequately assesses attachment strength, it should be strongly related to these behaviors. This study also examined the relation of each of the three component dimensions of the EA construct to each of the four attachment behaviors.

\section{Method}

One hundred and eighty-four undergraduate students, participating for class credit, completed one of two versions of a survey. To create variance on the EA measure, we asked respondents to report on a brand to which they had either a "weak" or a "strong attachment." Respondents were then asked to report on how they feel about the brand when they think about it and their relationship with it. Respondents indi- cated the extent to which each EA item described their emotional attachment to the brand.

Next, respondents answered a series of questions based on Hazan and colleagues' multi-item measures of the four attachment behaviors (Hazan \& Shaver, 1994; Hazan \& Zeifman, 1999) that were adapted in pretesting to be suitable to the brand relation context. These measures are multi-item Likert scales, ranging from 1 (strongly disagree) to 7 (strongly agree) wherein respondents rate the extent of their agreement concerning how a particular brand makes them feel.

\section{Results}

The internal consistencies of scales reflecting emotional attachment and the four attachment behaviors were good, with all Cronbach alpha scores at or above 0.87. A set of manipulation checks confirmed a significant difference in the strength of emotional attachment between strong $(M=4.06)$ and weak $(M=1.96, p<0.01)$ attachment conditions, verifying that we had created variance in emotional attachment through our manipulation.

Dimensional and item analyses revealed considerable variance in the 10 indicators of emotional attachment. However, all indicators of EA were significantly greater in the strong-attachment condition $(M \mathrm{~s}=4.35,3.85$, and 3.63, for Connection, Passion, and Affection, respectively) than in the weak-attachment condition $(1.73,2.02$, and 2.10 , respectively ( $p<.001$, in all cases). There was also considerable variance in the indicators of attachment behaviors. All behaviors were rated more highly in the strong-attachment condition $(M=4.35,3.84,3.63$, and 4.23 , for proximity, secure base, safe haven, and separation distress, respectively) than in the weak-attachment condition $(1.80,1.56,1.45$, and 1.60 , respectively ( $p<0.01$, in all cases). As shown in Table 2, the three EA dimensions were significantly correlated $(r>0.72, p<0.01)$, providing ancillary support for Study 3's finding of three oblique dimensions. As Table 2 also shows, the correlations between each of EA's three dimensions and the 4 attachment behaviors were also highly significant (all $r \mathrm{~s}$ 0.66-0.80, $p \mathrm{~s}<0.01$ ).

Based on the assumption that EA is composed of three first-order factors (see Study 3), we used structural equation modeling to examine the two models shown in Figure 2. Model 4 tests the independent contribution of each EA dimension to the prediction of the four attachment behaviors. This structure addresses whether each of the three EA dimensions makes an independent contribution to the prediction of the dependent variables. The significant coefficients between the three EA dimensions with the four attachment behaviors suggest they do (see the Model 4 in Figure 2).

However, Model 4 suffers from poor fit. The CMIN/DF statistic exceeds the rule-of-thumb cutoff of 5 , whereas each of the other fit statistics lies below the acceptable 0.90 value. We therefore revisited the approach taken in Model 3 (see Figure 1), which assumes that Affection, Pas- 
Model 1

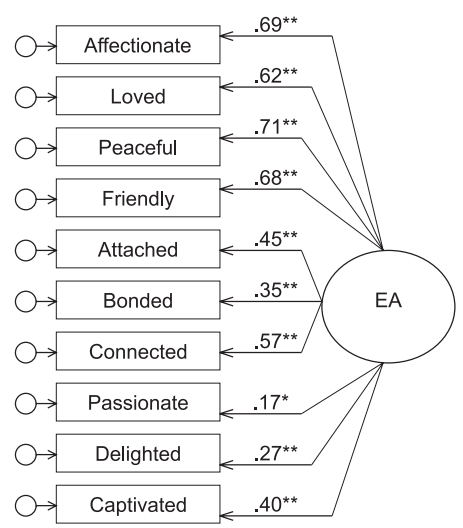

$\div^{2}=156.3, \mathrm{CMIN} / \mathrm{DF}=4.46 ; \mathrm{NFI}=.94 ; \mathrm{RFI}=.91 ; \mathrm{CFI}=.95$

Model 2

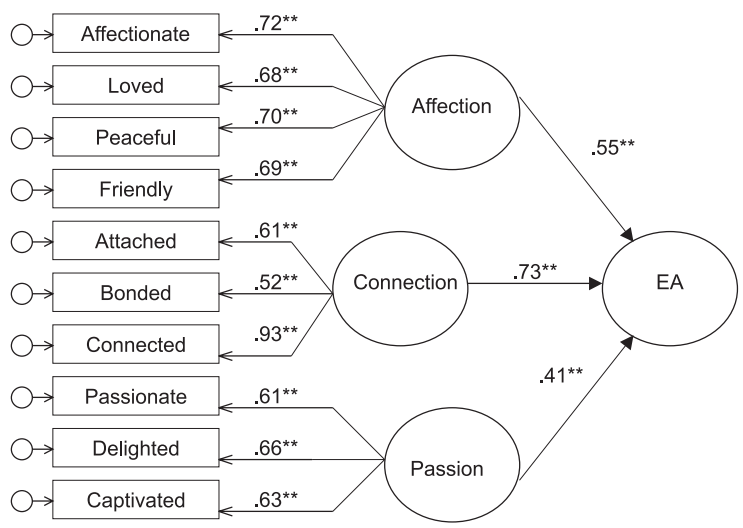

$\div 2=102.8 ; \mathrm{CMIN} / \mathrm{DF}=2.86 ; \mathrm{NFI}=.96 ; \mathrm{RFI}=.94 ; \mathrm{CFI}=.97$

\section{Model 3}

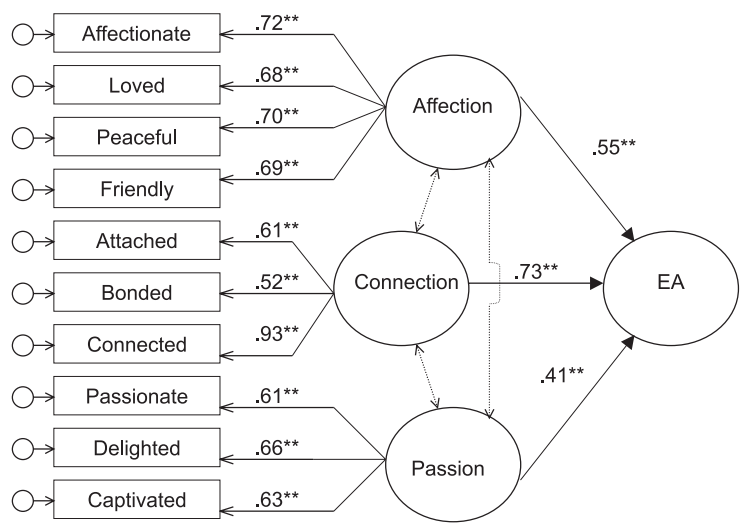

$\div^{2}=66.7 ; \mathrm{CMIN} / \mathrm{DF}=2.08 ; \mathrm{NFI}=.97 ; \mathrm{RFI}=.96 ; \mathrm{CFI}=.99$

FIGURE 1 Confirmatory factor analyses comparing three models of emotional attachment. Model 1 assumes that all items load on a single EA construct. Model 2 assumes three uncorrelated first-order factors reflecting a second-order EA construct. Model 3 assumes three correlated first-order factors reflecting a second-order EA construct. All coefficient values appear above the associated path (all standardized). Dotted lines represent correlations. $* p<.10 . * * p<.01$. 
TABLE 2

Study 4: Correlations Between Emotional Attachment Dimensions and Attachment Behaviors

\begin{tabular}{|c|c|c|c|c|c|c|c|}
\hline Subscale & 1 & 2 & 3 & 4 & 5 & 6 & 7 \\
\hline 1. Connection & - & 0.79 & 0.72 & 0.75 & 0.75 & 0.68 & 0.74 \\
\hline 2. Passion & & - & 0.75 & 0.77 & 0.77 & 0.72 & 0.80 \\
\hline 3. Affection & & & - & 0.69 & 0.68 & 0.66 & 0.70 \\
\hline 4. Proximity maintenance & & & & - & 0.82 & 0.77 & 0.90 \\
\hline 5. Emotional security & & & & & - & 0.86 & 0.85 \\
\hline 6. Safe haven & & & & & & - & 0.84 \\
\hline 7. Separation distress & & & & & & & - \\
\hline
\end{tabular}

Note. $\quad p \mathrm{~s}<0.01$

sion, and Connection each load onto a latent EA construct. This model, shown as Model 5 in Figure 2, reveals that all paths are significant and positive. EA is significantly related to proximity $(\gamma=0.92, p<0.01)$, seeking a secure base $(\gamma=0.91, p<0.01)$, finding a safe haven $(\gamma=0.88, p<$ $0.01)$, and separation distress $(\gamma=0.95, p<0.01)$. Furthermore, all of Model 5's fit statistics are acceptable $(\mathrm{CMIN} / \mathrm{DF}=3.50 ; \mathrm{NFI}=0.97 ; \mathrm{RFI}=0.95 ; \mathrm{CFI}=0.98)$. The chi-square value $\left(\chi^{2}=38.6\right)$ also suggests the fit of Model 5 is significantly better than the fit of Model $4\left(\chi^{2}=\right.$ $299.8, p<0.01)$. The joint effects of Affection, Passion, and Connection, captured in Model 5 by a single latent EA construct, better represent the data than Model 4, where each EA component independently predicts the criterion variables. These results provide good evidence of convergent validity for the EA scale and the representation of the three dimensions as first-order factors that load onto the global EA construct.

\section{Discussion}

Study 4 supports the convergent validity for the EA measure, as it relates strongly to each of the four attachment behaviors. Although attachment researchers in allied disciplines typically assess the attachment bond based on the existence of these behaviors, EA seems to capture the strength of this bond in a manner that is theoretically and empirically consistent with these behaviors, without the need to resort to the inference of emotional attachment from behaviors. Furthermore, while Model 4 suggests that each of the EA dimensions makes an important contribution to the outcome variables, Model 5 proposes that these factors are best represented as first-order factors indicating the latent EA construct.

\section{STUDY 5}

Study 5 had several objectives. First, we sought to assess the discriminant validity of the EA scale, showing that it is empirically distinguishable from similar constructs such as attitude favorability, satisfaction, and involvement. The sec- ond was to assess its predictive validity, showing that variation in EA scores correspond in theoretically consistent ways to outcome measures of strong brand attachments such as brand loyalty and willingness to pay a price premium. Finally, we sought to collect data from a more diverse sample of respondents to address issues of generalizability and external validity.

\section{Method}

One hundred and seventy-nine nonstudent respondents were solicited at a science museum and outside a restaurant and paid $\$ 5$ for participating in a study designed to assess "consumers' reactions to brands." The design was a $1 \times 3$ between-subjects design with approximately one third of the respondents asked to report on a brand to which they were "strongly," "moderately," or "weakly emotionally attached." Reporting on brands varying in strength of emotional attachment served to create variation in EA scores, necessary for examining its relation to constructs like satisfaction and attitude favorability. Respondents varied in age from 16 to 63 , with a mean age of 27 .

\section{Measures Designed to Assess Convergent and Discriminant Validity}

Support for the convergent validity of the EA scale would be provided by evidence that the measure is related to, but differentiated from, such constructs as attitude favorability, satisfaction, and involvement. These latter constructs were measured (in the following order) using items derived from prior research in marketing.

Brand attitude favorability. We adapted a measure of brand attitude $(\alpha=0.94)$ from Batra and Stayman (1990). Respondents used a four item, 7-point semantic differential scale ranging from 1 (bad) to 7 (good), 1 (unfavorable) to 7 (favorable), 1 (dislikeable) to 7 (likeable), and 1 (disagreeable) to 7 (agreeable) to describe their attitude favorability. 


\section{Model 4}

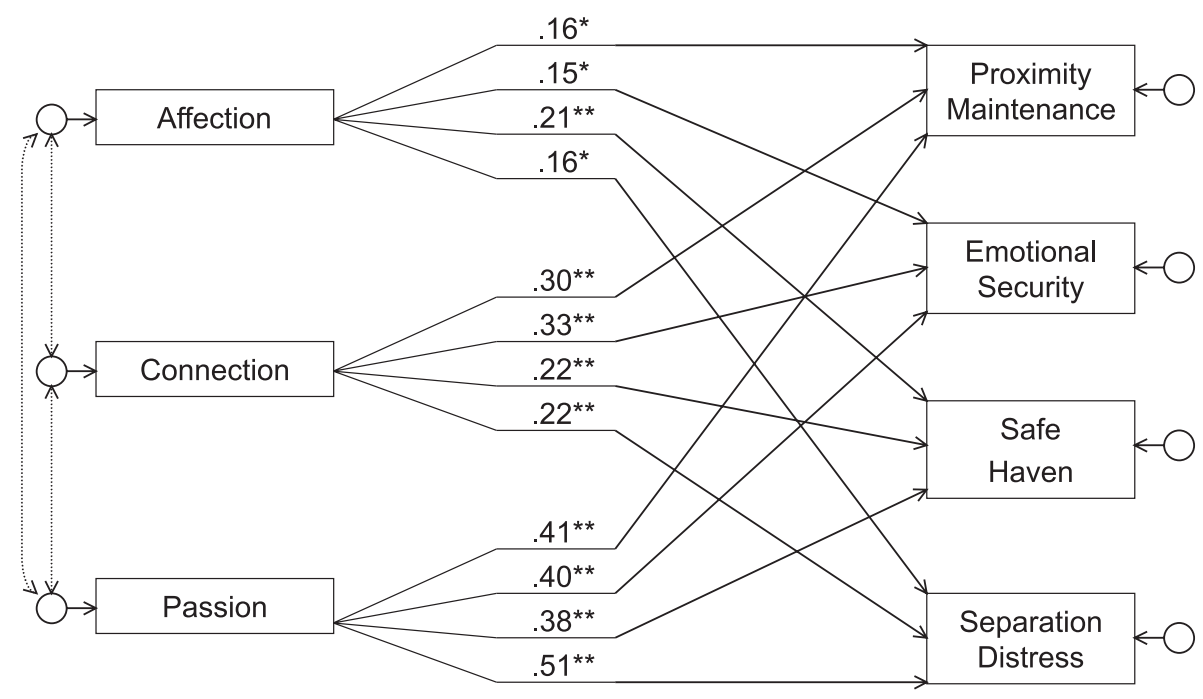

$$
\div 2=299.8 ; \mathrm{CMIN} / \mathrm{DF}=49.97 ; \mathrm{NFI}=.78 ; \mathrm{RFI}=.22 ; \mathrm{CFI}=.78
$$

\section{Model 5}

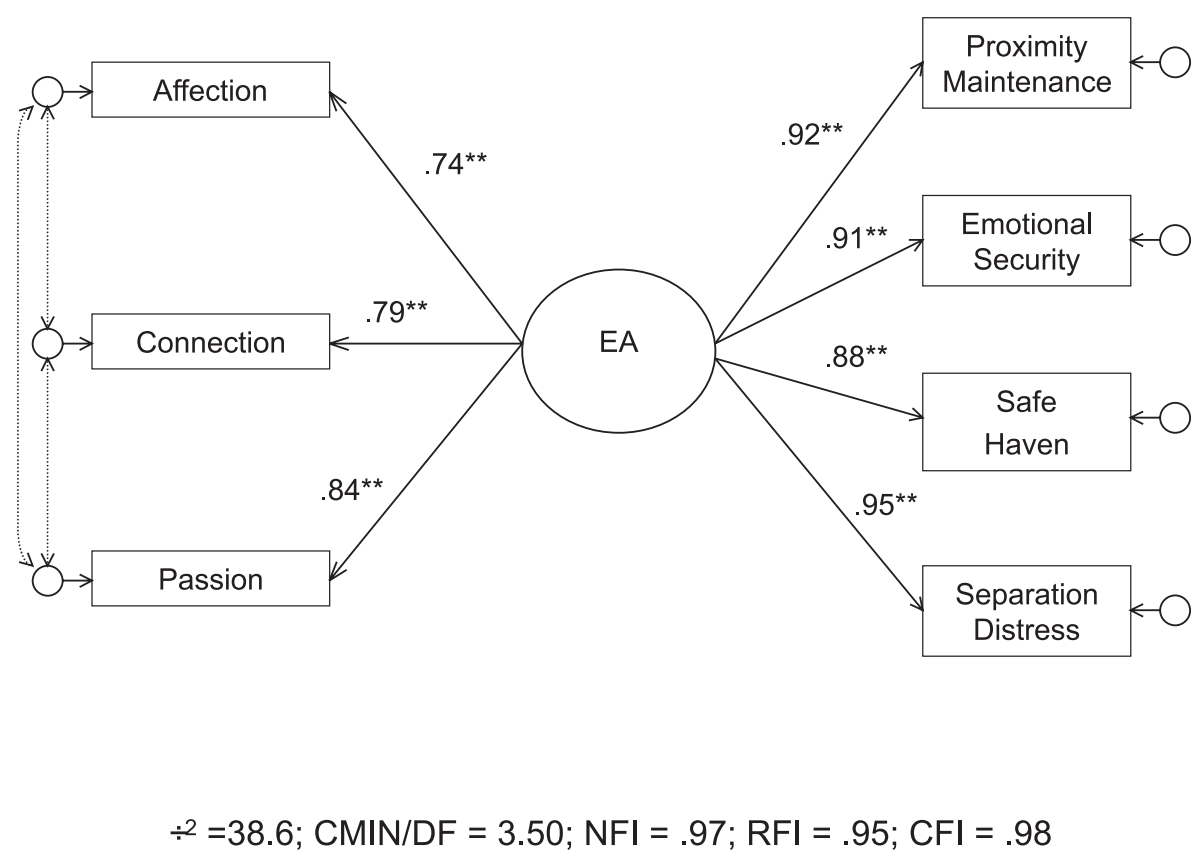

FIGURE 2 Assessing convergent validity in Study 4. Model 4 assumes three EA dimensions independently predict 4 attachment behaviors. Model 5 assumes three EA dimensions predict 4 attachment behaviors through a global EA construct. All coefficient values appear above the associated path (all standardized). Dotted lines represent correlations.

$* p<.05 . * * p<.01$ 
Satisfaction. We employed an 8-item subset of Mano and Oliver's (1993) measure of satisfaction $(\alpha=0.90)$. The scale uses a 7-point agreement scale and includes such items as "If I could do it again, I'd buy a different brand" and "This brand is exactly what I need."

Involvement. To measure involvement, we employed a subset of items from Zaichkowsky's (1985) involvement scale $(\alpha=0.94)$. Specifically, we asked respondents to use a 7-point semantic differential scale to rate their self-selected brand from 1 (unimportant to me) to 7 (important to me), 1 (of no concern to me) to 7 (of concern to me), 1 (irrelevant to me) to 7 (relevant to me), 1 (means nothing to me) to 7 (means a lot to me), 1 (useless to me) to 7 (useful to me), and 1 (insignificant to me) to 7 (significant to me).

\section{Measures Designed to Assess Predictive Validity}

Brand loyalty. We measured brand loyalty $(\alpha=0.86)$ with a metric adapted from Sirgy, Johar, Samli, and Clairborne (1991). Specifically, respondents used a 7-point semantic differential scale to answer the following three questions: (a) "How often have you bought this brand in the past?" on a scale of 1 (never) to 7 (always), (b) "How would you characterize your loyalty toward this brand?" on a scale of 1 (very weak) to 7 (very strong), and (c) "How does this brand compare to your 'ideal' brand?" on a scale of 1 (it is very far from my ideal brand) to 7 (it is very close to my ideal brand).

Willingness to pay a price premium. Finally, to determine if there was a relation between the strength of respondents' emotional attachment to a brand and their willingness to pay a price premium for that brand, we asked "Your brand is one of many brands in the product category. What do you estimate is the average price of brands in the product category?" Next, we asked what price respondents were willing to pay for their self-selected brand. Using these two data points, we calculated the percentage above or below the average price and used this figure as a measure of the willingness to pay a price premium. Responses across conditions ranged from approximately half to double the average price in the category.

\section{Control Variables and Manipulation Checks}

To control for the possibility that reported emotional attachment scores are affected by age, gender, or mood, we include three measures of these constructs. None were significant in the subsequently reported analyses and are not discussed further. To check whether respondents were reporting on a brand for which they had weak, moderate, or strong emotional attachment, we examined responses to a 3-item measure $(\alpha=0.94)$ : "My emotional attachment to the brand is 1 (weak) to 7 (strong), 1 (low) to 7 (high), and 1 (little) to 7 (a lot).

\section{Results}

Scale stability. The Cronbach's alpha reliability coefficient for this scale was 0.93 . We conducted a confirmatory factor analysis identical to Model 3 that represented EA as a second-order factor indicated by three interrelated first order factors, and obtained an identical pattern of results. Specifically, all paths were positive and significant, with good fit statistics $(\mathrm{CMIN} / \mathrm{DF}=3.38 ; \mathrm{NFI}=0.97 ; \mathrm{RFI}=0.95 ; \mathrm{CFI}=$ 0.98). Overall, these results suggest a good fit of the data and provide additional support for Model 3's conceptualization of the EA construct.

Manipulation check. Consumers' reported emotional attachment to the brand averaged 3.04, 4.03, and 5.18 when the manipulated levels were weak, moderate, and strong, respectively. All means were significantly different from one another $(p<0.01)$. Similarly, an analysis using the EA scale as the dependent variable revealed that respondents in the weak-attachment condition had lower EA scores $(M=2.86)$ than those in the moderate-attachment condition $(M=3.48 ; p$ $<.01$ ), and that respondents in the moderate-attachment condition had lower EA scores than those in the strong-attachment condition $(M=4.49 ; p<0.01)$.

Discriminant validity. The discriminant validity of the EA scale was assessed by an exploratory factor analysis using an oblique rotation that included the EA dimensions with items indicating the attitude favorability, satisfaction, loyalty, and involvement constructs. (We did not attempt a confirmatory factor analysis due to the considerable data requirements such an analysis would demand. Therefore, neither the number of factors nor which items loaded on which construct were specified a priori.) Table 3 reports the results of this analysis.

As shown, the factor analysis reveals five factors. Two factors represent attitude favorability and involvement, respectively, whereas another reflects the reverse-coded items for the satisfaction scale (i.e., reverse-coded "dissatisfaction" items). One factor is comprised of items from the loyalty and positive satisfaction scales. Finally, these results also show that Affection, Passion, and Connection load on a single EA factor.

The fact that satisfaction and loyalty loaded on a single factor is consistent with prior evidence that the two constructs are closely related (Oliver, 1999). Interestingly, we also found that dissatisfaction formed a separate factor from satisfaction, a result that is illuminated by prior research (Czepiel, Rosenberg, \& Akerele, 1977; Leavitt, 1977). 
TABLE 3

Study 5: Exploratory Factor Analysis (Oblique Rotation) with Emotional Attachment Dimensions and Measures of Brand Attitude, Satisfaction, Loyalty, and Involvement

\begin{tabular}{|c|c|c|c|c|c|}
\hline \multirow[b]{2}{*}{ Item } & \multicolumn{5}{|c|}{ Factor } \\
\hline & Involvement & Satisfaction and Loyalty & Brand Attitude & Dissatisfaction & Emotional Attachment \\
\hline Involvement 3 & 0.87 & 0.15 & 0.20 & 0.03 & 0.14 \\
\hline Involvement 6 & 0.86 & 0.11 & 0.21 & 0.03 & 0.14 \\
\hline Involvement 5 & 0.85 & 0.11 & 0.17 & 0.07 & 0.04 \\
\hline Involvement 4 & 0.82 & 0.08 & 0.22 & 0.02 & 0.25 \\
\hline Involvement 2 & 0.80 & 0.23 & 0.23 & 0.03 & 0.22 \\
\hline Involvement 1 & 0.72 & 0.36 & 0.17 & 0.08 & 0.26 \\
\hline Brand loyalty 2 & 0.29 & 0.83 & 0.13 & 0.14 & 0.05 \\
\hline Brand loyalty 1 & 0.16 & 0.82 & 0.03 & 0.09 & 0.02 \\
\hline Satisfaction 1 & 0.12 & 0.76 & 0.27 & 0.30 & 0.12 \\
\hline Brand loyalty 3 & 0.13 & 0.75 & 0.30 & 0.18 & 0.09 \\
\hline Satisfaction 2 & 0.14 & 0.65 & 0.37 & 0.28 & 0.19 \\
\hline Satisfaction 3 & 0.15 & 0.63 & 0.24 & -0.32 & 0.18 \\
\hline Brand attitude 3 & 0.26 & 0.23 & 0.87 & 0.08 & 0.11 \\
\hline Brand attitude 4 & 0.29 & 0.15 & 0.83 & 0.13 & 0.11 \\
\hline Brand attitude 2 & 0.27 & 0.31 & 0.82 & 0.13 & 0.05 \\
\hline Brand attitude 1 & 0.25 & 0.24 & 0.80 & 0.15 & 0.11 \\
\hline Satisfaction 4 & -0.03 & 0.13 & -0.20 & 0.78 & 0.14 \\
\hline Satisfaction 5 & -0.01 & 0.08 & 0.07 & 0.76 & 0.06 \\
\hline Satisfaction 6 & -0.05 & 0.18 & -0.15 & 0.75 & 0.02 \\
\hline Satisfaction 7 & -0.08 & 0.42 & -0.15 & 0.73 & 0.03 \\
\hline Satisfaction 8 & 0.04 & 0.16 & -0.08 & 0.69 & 0.26 \\
\hline Affection & 0.28 & 0.11 & 0.08 & 0.12 & 0.87 \\
\hline Passion & 0.25 & 0.11 & 0.21 & 0.07 & 0.86 \\
\hline Connection & 0.48 & 0.33 & 0.05 & 0.07 & 0.64 \\
\hline
\end{tabular}

TABLE 4

Study 5: Correlations Based on Table 3 Exploratory Factor Analysis Results

\begin{tabular}{|c|c|c|c|c|c|c|}
\hline Subscale & 1 & 2 & 3 & 4 & 5 & 6 \\
\hline 1. Emotional attachment & - & $0.57 *$ & $0.36^{*}$ & $0.38^{*}$ & -0.06 & $0.30^{*}$ \\
\hline 2. Involvement & & - & $0.54 *$ & $0.47 *$ & 0.13 & $0.25^{*}$ \\
\hline 3. Brand attitude & & & - & $0.56^{*}$ & $0.30 *$ & $0.18^{*}$ \\
\hline 4. Loyalty and satisfaction & & & & - & $0.49 *$ & $0.40 *$ \\
\hline 5. Dissatisfaction & & & & & - & 0.11 \\
\hline 6. Price premium & & & & & & - \\
\hline
\end{tabular}

$* p<0.05$.

Convergent validity. Table 4 shows the correlations between EA and the revealed factors from this analysis. As expected, correlations of these factors with the EA scale were significant but generally modest in size.

Predictive validity of the EA scale. To assess the predictive validity of the EA scale, we constructed several structural models. Model 6 in Figure 3 depicts each of the 10 EA items as loading onto 3 interrelated first-order factors, which in turn predict brand loyalty and price premium. The results of this model (Figure 3) show that Connection, Affection, and Passion are each significant or marginally significant (all $p s<0.10)$ in predicting Brand Loyalty and Price Premium. With the exception of the RFI statistic (which is nearly adequate), all the indexes suggested good fit.
Model 7 (in Figure 3) depicts a similar model, except that each of the first-order factors (Affection, Connection, and Passion) loads onto a global EA variable, as with Model 3 in Study 3 and Model 5 in Study 4. These results also show that EA is a good predictor of both Brand Loyalty and Price Premium. Based on the improved CMIN/DF, CFI, NFI, and RFI statistics (but not the change in the chi-square statistic, which is not significant), we can also see that Model 7 better describes the data than one in which Affection, Passion, and Connection are set to independently predict the outcome measures. Although Model 6 confirms that each EA dimension makes an independent contribution in the prediction of brand loyalty and price premium, Model 7 suggests the most parsimonious conceptualization of EA is as a global second-order factor. 
$\underline{\text { Model } 6}$

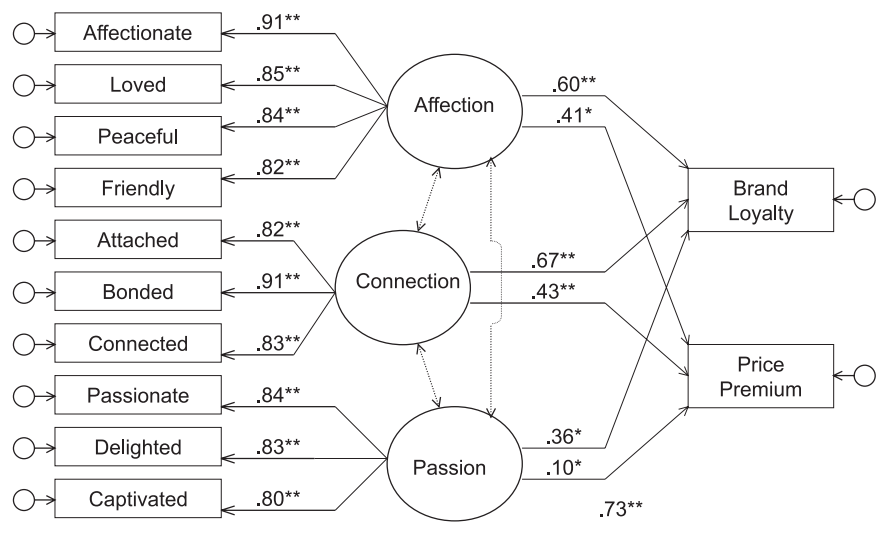

$\div 2=137.4 ; \mathrm{CMIN} / \mathrm{DF}=2.92 ; \mathrm{NFI}=.91 ; \mathrm{RFI}=.87 ; \mathrm{CFI}=.94$

$\underline{\text { Model } 7}$

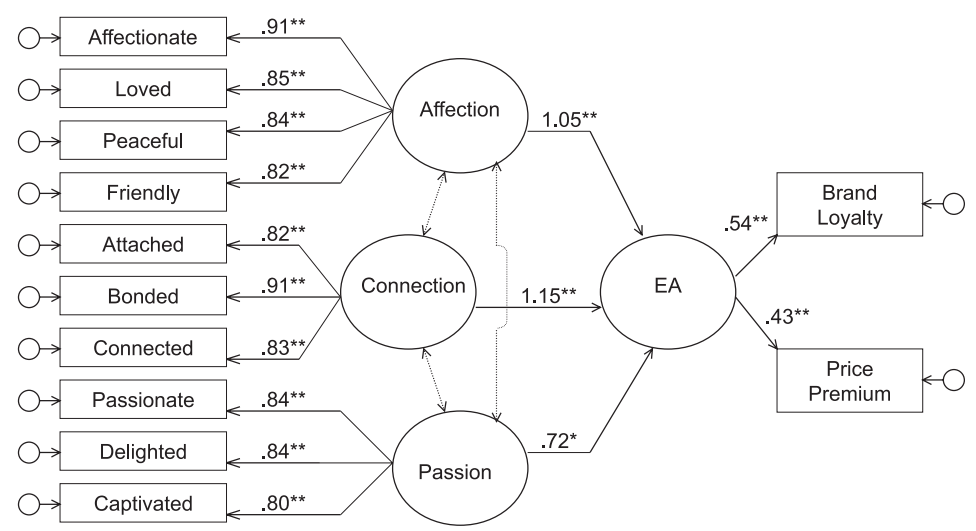

$\div 2=138.4 ; \mathrm{CMIN} / \mathrm{DF}=2.82 ; \mathrm{NFI}=.97 ; \mathrm{RFI}=.95 ; \mathrm{CFI}=.98$

Model 8

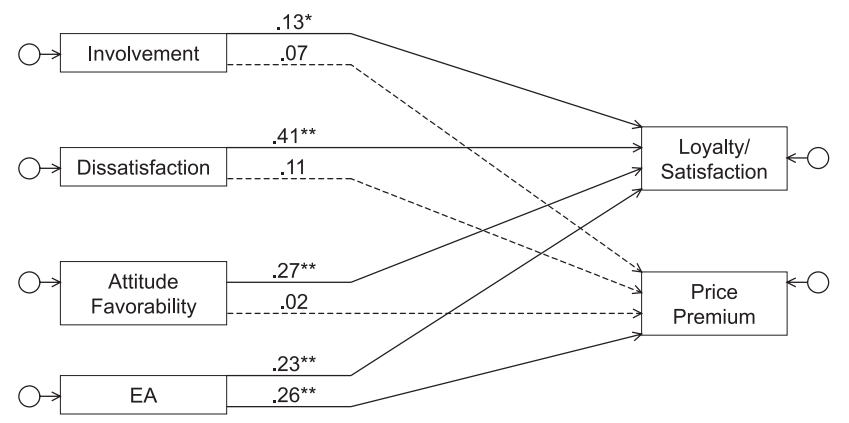

$\div^{\circ}=17.0 ; \mathrm{CMIN} / \mathrm{DF}=16.99 ; \mathrm{NFI}=.94 ; \mathrm{RFI}=.16 ; \mathrm{CFI}=.94$

FIGURE 3 Three models from Study 5 assessing predictive validity of EA scale. Model 6 assumes three interrelated EA dimensions predict brand loyalty and price premium directly. Model 7 assumes three interrelated EA dimensions predict brand loyalty and price premium through a second-order EA construct. Model 8 illustrates that EA predicts two outcome measures in a model also including measures of attitude, satisfaction, and involvement. All coefficient values appear above the associated path (all standarized). Dotted lines represent correlations. Model 8: predictor variable error terms are modeled as correlated, and insignificant paths are shown by dotted lines. 
Finally, Model 8 in Figure 3 addresses the question of whether EA is a significant predictor of important outcome measures, even while other known antecedents are included in the model. We were unable to conduct a full measurement or structural model given the data requirements such an exercise would demand. Instead, we employ composite measures, a move which considerably reduces the number of paths to be estimated. Because our Factor Analysis reported in Table 3 revealed 5 factors, we constructed the model to reflect this result, allowing all the measures, including the known antecedents to the outcome measures, to enjoy increased internal consistency. We use the composite "loyalty" (which shows good internal consistency) in Models 6 and 7 because these models do not include measures with which loyalty seems confounded (i.e., satisfaction, as suggested by the factor analysis reported previously). In Model 8, we also allow the error terms of the predictors to be correlated.

The fit statistics of this model are mixed (CMIN/DF = 17.0; NFI $=0.94 ; \mathrm{RFI}=0.16 ; \mathrm{CFI}=0.94$ ), which is partly a function of the fact that the model is not capturing some of the variables that may affect brand loyalty and price premium. The very small RFI statistic indicates not only that the model fits poorly but also that it is not parsimonious, suggesting that a model with fewer predictor variables would obtain better fit. However, our goal is to demonstrate EA's predictive power, not to explain all possible influences on the outcome variables. As such the more relevant issue concerns the value of the paths between EA and the outcome measures. These results (see Figure 3 ) show that EA continues to predict loyalty and satisfaction $(\gamma=0.23, \mathrm{p}<0.01)$ and willingness to pay a price premium $(\gamma=0.26, p<0.01)$ even when the other antecedents are included in the analysis. Furthermore, EA is the only significant predictor of a consumer's willingness to pay a premium, underscoring the bottom-line potential to marketers who successfully recognize or create strong consumer-brand attachments.

Structural equation modeling provides one of several ways to examine the predictive validity of the EA scale. We also conducted a set of hierarchical regression analyses that included the attitude favorability, satisfaction, and involvement measures as the first set of predictor variables, followed by EA in the second stage. The dependent variables for these hierarchical regressions were brand loyalty and willingness to pay a price premium, respectively. This approach is a conservative test of EA's independent predictive power as it allocates as much variance to the predictor variables entered in the previous step before considering EA's contribution. Whereas structural modeling is a form of simultaneous analysis, hierarchical regression is sequential. The results for brand loyalty showed that EA remained significant even when the variance in these other factors was accounted for first $(\beta=0.14, p<0.02)$. A second hierarchical regression analysis using price premium as the dependent variable also showed that EA remained significant $(\beta=0.25, p<0.01)$ even after accounting for the variance explained by attitude favorability, satisfaction, and involvement.

\section{Discussion}

Study 5 supports the stability as well as discriminant and predictive validities of the EA scale. The data support the conceptualization of emotional attachment as a second order factor comprised of three first order factors: Connection, Affection, and Passion. They also support the conceptualization of EA as empirically discriminable from such constructs as attitude favorability, satisfaction, and involvement. Finally, the results support the predictive validity of the scale, showing that its influence on outcomes (brand loyalty and willingness to pay a price premium) is theoretically consistent with attachment theory. The measure adds explanatory power to the prediction of these factors even when the variance in attitudes, involvement, and satisfaction is accounted for first.

\section{GENERAL DISCUSSION}

The primary objective of this article is to develop a new measure reflecting the strength of consumers' emotional attachments to brands. Based on the premise that consumers are able to articulate the nature of their emotional attachment to brands, we identified a set of emotion items thought to potentially indicate attachment. The finalized 10 -item scale reflects three interrelated first order factors labeled Affection, Passion, and Connection that map onto the second-order emotional attachment construct. The existence of the three first-order factors and their mapping onto the second order EA construct is consistent across samples and studies.

The scale's convergent validity was indicated in Study 4 by its ability to predict four behaviors reflecting attachments. Evidence of discriminant validity was obtained found in Study 5, where EA was empirically distinguishable from measures of attitude favorability, satisfaction, and involvement. Study 5 also offered evidence of predictive validity, showing that EA predicts outcomes theoretically linked with strong attachments. In fact, it had predictive power beyond that explained by brand attitudes, satisfaction, and involvement.

These results must be tempered by several caveats. First, although our results suggest that EA predicts brand loyalty, we do not wish to suggest that emotional attachment is the only driver of loyalty or that loyalty requires emotional attachment. Similarly, though EA predicts consumers' willingness to pay a price premium, we do not propose that it is the best or only predictor of this variable. Rather, we suggest that the emotional attachment scale is valid because it predicts these outcomes in a manner consistent with attachment theory and that it is useful because it explains variance beyond attitude, involvement, and satisfaction. 
Second, although we were successful in creating variance in emotional attachment, we were not successful in having respondents report on brands reflecting extreme levels of emotional attachment. In the strong attachment conditions of Studies 4 and 5, means on EA were approximately 4.0 to 4.5 on a 7-point scale. Though the standard deviations in reported attachment scores in these conditions were relatively high, the attachment scores are best characterized as "relatively strong" compared to the weaker attachment conditions. The results may suggest that (a) extremely strong attachments are rare in a brand context or that (b) managers have considerable leeway to enhance the strength of consumers' emotional attachments to brands.

\section{Future Research}

In this research, consumers were asked to self-select a brand, corresponding to varying degrees of emotional attachment as directed by the respective instrument condition that they received. An alternative data collection methodology would be to use a common brand (e.g., Coca-Cola) and ask consumers to report their emotional attachment to only that specific brand. One advantage of this methodology is that the brand would be constant across all emotional attachment conditions. We attempted such a data collection effort in several pretests, but results had too little variation and predominantly weak attachment scores to efficiently examine the realm of strong attachments. This was probably due to the fact that we employed a relatively homogeneous population of respondents (students) who had similarly weak attachments to the common brands selected. Nevertheless, extensions to this study could examine the generalizability of our results to populations that are more heterogeneous and for whom there would be variation in emotional attachment to a common brand.

Additional work on the EA construct requires future research into its boundary conditions and the diagnosticity of the EA measure to marketers. One boundary condition concerns the types of brands and purchase situations most germane to emotional attachment. Although our studies were not designed to directly assess boundary conditions, indirect evidence from Study 5 suggests brands in the strong emotional attachment condition tended to be more high involvement and symbolically or hedonically related (e.g., the Body Shop, Hermet Lang, BMW, BeBe, Prada, and Oakley) than low involvement or functionally related (e.g., AT\&T, All, Ziploc).

We did not design our studies to examine differences between functional brands and symbolic or hedonic ones. However, the possibility that one would find higher emotional attachment scores for symbolic brands is perhaps not surprising because the notion of an attachment implies a connection with the self, and symbolic products are valued for what they say about the self. Moreover, such brands are likely to be characterized as "high involvement" products as they are meaningful and significant to individuals (Zaichkowsky, 1985). Further research should systematically assess whether strong emotional attachments are specific to brands that meet certain types of needs and whether they require a certain level of product involvement.

The relation of emotional attachment to product involvement is not surprising given the relation of involvement to emotional attachment discussed conceptually and demonstrated empirically. One might therefore surmise that the EA scale provides a more diagnostic indicator of attachment for high involvement products, as it can separate those brands for which involvement is high but emotional attachment is low from those for which both involvement and emotional attachment are high. It might only be in the latter case that brand loyalty and willingness to pay a price premium are both strong.

It is also interesting that the brands respondents chose in Study 5 tended to be at the level of the company brand, as opposed to a specific product-brand. It is possible that corporate brands are more salient, memorable, and hence more likely to be reported (irrespective of the level of attachment). However, further research is needed to determine whether the level of the brand (individual product or corporate) is relevant to the level of emotional attachment that consumers develop.

A final issue concerns the types of purchase situations for which each emotional attachment dimension might be most relevant. For example, a consumer whose brand attachment is characterized as high in affection might choose to give the brand as a gift to significant others, as the affection characterizing the brand may symbolize the affection the consumer has toward the gift recipient. A consumer whose attachment is characterized as high in passion, however, might be likely to purchase the brand impulsively and to exceed the budget allocated for purchase. Finally, a consumer whose brand attachment is characterized as high in connection might expend considerable effort to preserve that brand, perhaps through brand collections and ritualized care of the brand. The purchase situations relevant to each dimension of attachment therefore deserve additional attention.

\section{REFERENCES}

Adams-Price, C., \& Greene, A. L. (1990). Secondary attachments and adolescent self concept. Sex Roles, 22, 187-198.

Ainsworth, M. D. S., Blehar, M., Waters, E., \& Wall, S. (1978). Patterns of attachment: A psychological study of the strange situation. Hillsdale, $\mathrm{NJ}$ : Lawrence Erlbaum Associates, Inc.

Alperstein, N. M. (1991). Imaginary social relationships with celebrities appearing in television commercials. Journal of Broadcasting and Electronic Media, 35, 43-58.

Aron, A., Aron, E. N., \& Allen, J. (1998). Motivations for unreciprocated love. Personality and Social Psychology Bulletin, 24, 787-797.

Aron, A., \& Westbay, L. (1996). Dimensions of the prototype of love. Journal of Personality and Social Psychology, 70, 535-551. 
Baldwin, M. W., Keelan, J. P. R., Fehr, B., Enns, V., \& Koh-Rangarajoo, E. (1996). Social-cognitive conceptualization of attachment working models: Availability and accessibility effects. Journal of Personality and Social Psychology, 71, 94-109

Ball, A. D., \& Tasaki, L. H. (1992). The role and measurement of attachment in consumer behavior. Journal of Consumer Psychology, 1, 155-172.

Batra, R., \& Stayman, D. M. (1990). The role of mood in advertising effectiveness. Journal of Consumer Research, 17, 203-214.

Belk, R. (1988). Possessions and the extended self. Journal of Consumer Research, 15, 139-168.

Bowlby, J. (1979). The making and breaking of affectional bonds. London: Tavistock.

Bowlby, J. (1980). Loss: Sadness and depression. New York: Basic Books.

Brennan, K. A., Clark, C. L., \& Shaver, P. R. (1998). Self-report measurement of adult attachment: An integrative overview. In J. A. Simpson \& W. S. Rholes (Eds.), Attachment theory and close relationships (pp. 46-76). New York: Guilford Press.

Churchill, G. A., Jr. (1979a). Marketing research: Methodological foundations. Hinsdale, IL: The Dryden Press.

Churchill, G. A., Jr. (1979b). A paradigm for developing better measures of marketing constructs. Journal of Marketing Research, 16, 64-73.

Collins, N. L., \& Read, S. J. (1990). Adult attachment, working models and relationship quality in dating couples. Journal of Personality and Social Psychology, 58, 644-663.

Collins, N. L., \& Read, S. J. (1994). Cognitive representations of attachment: The structure and function of working models. In K. Bartholomew \& D. Perlman (Eds.), Advances in personal relationships (pp. 53-90). London: Jessica Kingsley.

Czepiel, J. A., Rosenberg, L. J., \& Akerele, A. (1977). The study of consumer satisfaction: Addressing the "so what" questions. In H. K. Hunt (Ed.), Conceptualization and measurement of customer satisfaction and dissatisfaction (pp. 92-119). Cambridge, MA: Marketing Science Institute and National Science Foundation.

Drigotas, S. M., \& Rusbult, C. E. (1992). Should I stay or should I go? A dependence model of breakups. Journal of Personality and Social Psychology, 62, 62-87.

Dwyer, R. F., Schurr, P. H., \& Oh, S. (1987). Developing buyer-seller relationships. Journal of Marketing, 51, 11-28.

Feeney, J. A., \& Noller, P. (1996). Adult attachment. London: Sage.

Fehr, B., \& Russell, J. A. (1991). The concept of love viewed from a prototype perspective. Journal of Personality and Social Psychology, 60, 425-438.

Garbarino, E., \& Johnson, M. S. (1999). The different roles of satisfaction, trust, and commitment in customer relationships. Journal of Marketing, 63, 70-87.

Hair, J. F. (1995). Multivariate data analysis. New York: Macmillan.

Hazan, C., \& Shaver, P. R. (1987). Romantic love conceptualized as an attachment process. Journal of Personality and Social Psychology, 52, 511-524.

Hazan, C., \& Shaver, P. R. (1994). Attachment as an organizational framework for research on close relationships. Psychological Inquiry, 5, 1-22.

Hazan, C., \& Zeifman, D. (1994). Sex and the psychological tether. In K. Bartholomew \& D. Perlman (Eds.), Advance in personal relationships: Vol. 5. Attachment processes in adulthood (pp. 151-177). London: Jessica Kingsley.

Hazan, C., \& Zeifman, D. (1999). Pair bonds as attachments. In J. Cassidy \& P. R. Shaver (Eds.), Handbook of attachment (pp. 336-354) New York: Guilford.

Hendrick, C., \& Hendrick, S. S. (1989). Research on love: does it measure up? Journal of Personality and Social Psychology, 56, 784-794.

Hill, R. P., \& Stamey, M. (1990). The homeless in America: An examination of possessions and consumption behaviors. Journal of Consumer Research, 17, 303-322.

Hirschman, E. C. (1994). Consumers and their animal companions. Journal of Consumer Research, 20, 616-633.

Holmes, J. G. (2000). Social relationships: The nature and function of relational schemas. European Journal of Social Psychology, 30, 447-495.
Johnson, D., \& Rusbult, C. E. (1989). Resisting temptation: Devaluation of alternative partners as a means of maintaining commitment in close relationships. Journal of Personality and Social Psychology, 57, 967-980.

Kamptner, N. L. (1991). Personal possessions and their meanings-A life-span perspective. Journal of Social Behavior and Personality, 6, 209-228.

Kleine, R. E., III, Kleine, S. S., \& Kernan, J. B. (1993). Mundane consumption and the self: A social identity perspective. Journal of Consumer Psychology, 2, 209-235.

Kleine, S. S., Kleine, R. E., III, \& Allen, C. T. (1995). How is a possession "me" or "not me": Characterizing types and an antecedent of material possession attachment. Journal of Consumer Research, 22, 327-343.

Kleine, S., Kleine, R. E., \& Kernan, J. B. (1989). These are a few of my favorite things - Toward an explication of attachment as a consumer-behavior construct. Advances in Consumer Research, 16, 359-366.

Leavitt, C. (1977). Consumer satisfaction and dissatisfaction: Bipolar or independent. In K. Hunt (Ed.), Conceptualization and measurement of customer satisfaction and dissatisfaction (pp. 120-128). Cambridge, MA: Marketing Science Institute.

Mano, H., \& Oliver, R. L. (1993). Assessing the dimensionality and structure of the consumption experience: Evaluation, feeling and satisfaction. Journal of Consumer Research, 20, 451-466.

Mehta, A. R., \& Belk, R. W. (1991). Artifacts, identity and transition-Favorite possessions of Indians and Indian immigrants to the United States. Journal of Consumer Research, 17, 398-411.

Mick, D. G., \& DeMoss, M. (1990). Self-gifts: Phenomenological insights from four contexts. Journal of Consumer Research, 17, 322-333.

Mikulincer, M., Hirschberger, G., Nachmias, O., \& Gillath, O. (2001). The affective component of the secure base schema: affective priming with representations of proximity maintenance. Journal of Personality and Social Psychology, 81, 305-321.

Miller, R. S. (1997). Inattentive and contented: Relationship commitment and attention to alternatives. Journal of Personality and Social Psychology, 73, 758-766.

Moorman, C., Deshpande, R., \& Zaltman, G. (1993). Factors affecting trust in market research relationships. Journal of Marketing, 57, 81-102.

Morgan, R. M., \& Hunt, S. D. (1994). The commitment-trust theory of relationship marketing. Journal of Marketing, 58, 20-39.

Nunally, J. C. (1978). Psychometrictheory. New York: McGraw-Hill

Oliver, R. (1999). Whence consumer loyalty? Journal of Marketing, 63, 33-44.

Park, C. W., \& Mittal, B. (1985). A Theory of involvement in consumer behavior: Problems and issues. Research in Consumer Behavior, 1, 201-232.

Richins, M. L. (1994a). Special possessions and the expression of material values. Journal of Consumer Research, 21, 522-533.

Richins, M. L. (1994b). Valuing things: The public and private meanings of possessions. Journal of Consumer Research, 21, 504-521.

Rubinstein, R. L., \& Parmelee, P. A. (1992). Attachment to place and the representation of the life course by the elderly. In I. Altman \& S. M. Low (Eds.), Place attachment (pp. 139-163). New York: Plenum.

Rusbult, C. (1983). A longitudinal test of the investment model: The development (and deterioration) of satisfaction and commitment in hetrosexual involvements. Journal of Personality and Social Psychology, 45, $172-186$

Sable, P. (1995). Pets, attachments, and well-being across the life cycle. Social Work, 40, 334-341.

Schouten, J. W., \& McAlexander, J. H. (1995). Subcultures of consumption: An ethnography of the new bikers. Journal of Consumer Research, 22, 43-61.

Schultz, S. E., Kleine, R. E., \& Kernan, J. B. (1989). These are a few of my favorite things: Toward an explication of attachment as a consumer behavior construct. Advances in Consumer Research, 16, 359-366.

Shaver, P. R., Schwartz, J., Kirson, D., \& O'Conner, C. (1987). Emotion knowledge: Further exploration of a prototype approach. Journal of Personality and Social Psychology, 52, 1061-1086. 
Sheppard, B. H., Hartwick, J., \& Warshaw, P. R. (1988). The theory of reasoned action: A meta-analysis of past research with recommendations for modifications and future research. Journal of Consumer Research, 15, 325-343.

Shimp, T. A., \& Madden, T. J. (1988). Consumer-object relations: A conceptual framework based analogously on sternberg's triangular theory of love. Advances in Consumer Research, 15, 163-168.

Sirgy, J. M., Johar, J. S., Samli, A. C., \& Claiborne, C. B. (1991). Self-congruity versus functional congruity: Predictors of consumer behavior. Journal of the Academy of Marketing Science, 19, 363-375.

Slater, J. S. (2000, October). Collecting brand loyalty: A comparative analysis of how Coca-Cola and Hallmark use collecting behavior to enhance brand loyalty. Paper presented at the Annual Conference of the Association of Consumer Research, Salt Lake City, UT.

Sternberg, R. J. (1986). A triangular theory of love. Psychological Review, 93, 119-135.

Sternberg, R. J. (1987). Liking vs. loving: A comparative evaluation of theories. Psychological Bulletin, 102, 331-345.
Trinke, S. J., \& Bartholomew, K. (1997). Hierarchies of attachment relationships in young adulthood. Journal of Social and Personal Relationships, 15, 603-625.

van Lange, P. A. M., Rusbult, C. E., Drigotas, S. M., \& Arriaga, X. B. (1997). Willingness to sacrifice in close relationships. Journal of Personality and Social Psychology, 72, 1373-1396.

Wallendorf, M., \& Arnould, E. J. (1988). "My favorite things": A cross-cultural inquiry into object attachment, possessiveness and social linkage. Journal of Consumer Research, 14, 531-547.

Weiss, R. S. (1988). Loss and recovery. Journal of Social Issues, 44, 37-52.

Zaichkowsky, J. L. (1985). Measuring the involvement construct. Journal of Consumer Research, 12, 3441-352.

Received: February 4, 2003

Revision received: November 4, 2003

Accepted: January 30, 2004 